\title{
Proposed Synergies between Indigenous and Modern Systems \\ of Environmental Education in Addressing Development Planning in Zambia
}

\author{
by \\ Mulambwa Mwanang'ono
}

\section{ABSTRACT}

The study drew inspiration from the need to counteract the ensuing failures of modern systems in addressing development challenges especially at local level despite several efforts by government to invest resources in poverty reduction and general developmental interventions. The study identified the alienation of indigenous knowledge systems in the mainstream modern systems of Environmental Education (EE) and development planning as a compounding problem that accounted for development stagnation in the communities. This alienation created the gap in knowledge since modern systems were generally found to be inadequate in addressing developmental issues, particularly at a local level. The lack of local relevance of most modern systems justified the call for integration of indigenous systems.

The study focused on the need to establish linkages between the modern and indigenous systems of environmental education and their influence on development planning in Zambia. In so doing, the study proposed an approach to remedy the alienation of indigenous systems in the mainstream processes of EE and development planning by suggesting a synergy between the two systems. The study involved an assessment of some inherent policies, strategies, processes, methodologies and perceptions about EE and development planning. It, therefore, largely dealt with nonconcrete ideas to which the reader is introduced. This point is crucial in appreciating the main orientation of the study.

Descriptive research design was applied with qualitative approaches. The respondents were purposively sampled and included government officers and other modern experts, NGOs, and traditional leaders. A comparative analysis of modern systems was further made through a global dimension where the Zambian modern system and that of selected foreign countries, Germany and Montenegro were reviewed.

The study established that the approaches applied in environmental education and general nature conservation were related to the country's guiding principles which also reflected the overall vision, where it existed. Furthermore, a number of environmental policy instruments were examined and the following were identified as the main instruments:

- Direct regulation

- Indirect regulation

- Self-regulation, and

- A combination of the above instruments. 
From the study results, differences in perceptions of and approaches to environmental education were evident at both country and individual levels. For instance, while in Zambia, environmental education was a school subject, in Germany it was not but its ideals were generally incorporated in the teaching of all subjects. In Montenegro, too, there was no school subject called environmental education but the concept had greatly influenced the school curriculum such that emphasis was put on environmental content in all the subjects, focusing more on human-nature relationships.

The study also showed that direct regulation had been prioritised in Zambia compared to self-regulation and this had a bearing on public participation in development decision-making processes which are largely carried out in the planning cycles. Varying perceptions were also identified at individual level among the modern experts interviewed both in Zambia and those from other countries. However, existing opportunities for synergy formulation at all levels were identified and based on these a synergy was suggested.

Arising from the above observations the study recommended, among other things, that the modern systems should adopt a broadened approach that promotes direct contact with nature from a multi-dimensional perspective. This would also call for curriculum and planning systems review to create an enabling education policy and planning framework that would provide practical support to such an approach. The promotion of culture, which was identified as a storage device for indigenous knowledge, was also recommended to be prioritised.

\section{BACKGROUND}

Numerous efforts have been made by the Zambian government and many other governments in the world, to invest in programmes and activities that are aimed at facilitating development and improve human welfare. These efforts, however, have registered insignificant impact on the lives of the majority of the citizens and have in some cases worsened the situation. The appropriateness and relevance of the strategies and methodologies applied by government in trying to bring about development have a bearing on the outcome of these development interventions. In this case, modern development planning and education methodologies in use may not adequately and appropriately respond to community felt needs especially that the involvement of communities in these modern systems has been negligible. As such, these efforts have been of negligible significance in addressing pressing environmental challenges that undermine human aspirations for holistic sustainable development and environmental sustainability.

The failure of current modern systems to address environmental and development concerns could partially be attributed to the alienation of indigenous knowledge systems which worked well in the past. This alienation created inherent obstacles which this study identified as a compounding problem especially that the modern systems were generally of insignificant relevance to addressing local environmental and development challenges. It was, therefore, imperative to analyse inherent principles and approaches of modern and indigenous systems so as to devise alternative strategies of tapping good elements from both systems and create a hybrid system. 


\section{GENERAL AIM OF THE STUDY}

The study aimed at analysing Environmental Education (EE) from the perspectives of both indigenous and moderns systems vis-à-vis their potential synergetic contribution to addressing development planning in Zambia; and to generate theoretical and pragmatic perspectives from which a synergy of the two systems could be suggested.

In the context of this study a synergy is a combination of two or more attributes, ideas, systems or approaches aimed at enhancing the effectiveness and efficiency of the existing ones. It is basically a cross-pollination of identified positive attributes from different methodologies.

\section{OBJECTIVES}

- To establish the indigenous and modern systems of environmental education in addressing development planning in Zambia;

- To establish the interface between Indigenous and Modern systems of Environmental Education (EE) in confronting Development Planning in Zambia;

- To devise a harmonised EE system comprising principles from both Indigenous and Modern systems relevant to dealing with Development Planning in Zambia.

\section{RESEARCH QUESTIONS}

- What are the modern and indigenous environmental education systems that can be applied in addressing development planning in Zambia?

- What is the interface between indigenous and modern systems of environmental education when addressing development planning in Zambia?

- What synergy of EE systems can be formulated encompassing principles of both modern and indigenous systems?

\section{RATIONALE}

The study will contribute to bridging the gap between the available systems of EE being applied in development planning in Zambia and the indigenous systems and enhance the relevance of mainstream systems to local situations. Various stakeholders may also benefit from this study in many ways.

\section{METHODOLOGY}

- Research Design: the study adopted descriptive design and qualitative approach since it dealt with people's perceptions, systems, policies and other abstract ideas that are not necessarily quantifiable.

- Research Instruments: Observations and interview guides were used in both individual and group discussions.

- Target Population and Sampling: government departments, institutions, NGOs, individual experts, and traditional authorities were targeted and purposively sampled. Eighty-four subjects were involved categorised as per pie chart in Figure 1 below. 


\section{Figure 1: Respondent Analysis: Summary of Respondents by Classification}

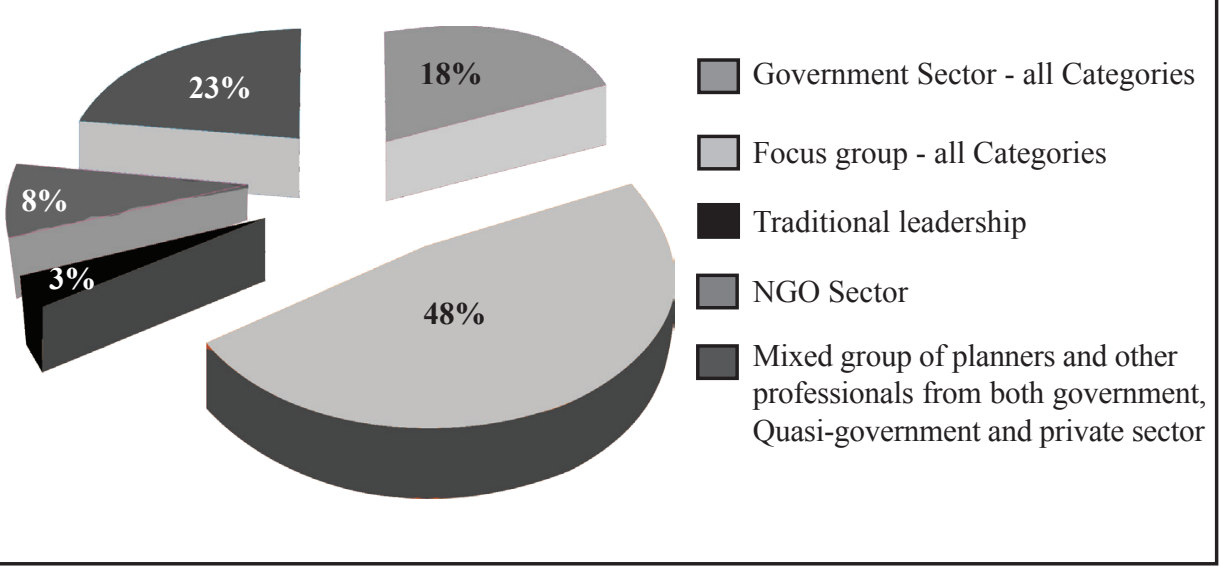

Source: Field Data, 2012

\section{PRESENTATION AND DISCUSSION OF STUDY FINDINGS}

\subsection{Introduction}

The study findings presented here are categorised into thematic areas that address specific issues raised in the study objectives and research questions. The main themes covered in the results discussion are the interface between the two systems, key environmental education systems or approaches used in modern and indigenous systems, prospects for synergy formulation at both global and local levels, and finally a proposed synergy that accounts for positive aspects of the two systems.

\subsection{The Interface between Indigenous and Modern Knowledge Systems}

When applied to environmental education and development planning, indigenous and modern systems could be analysed from the perspectives of their priorities vis-à-vis the concept of conservation and development. How conservation relates to development has a bearing on the philosophical underpinnings of a system, be it modern or indigenous. It also molds the relationship between humanity and nature. This relationship has some influence on the discovery and sharing of knowledge. Environmental education approaches applied by a system could therefore be a reflection of the inherent relations between nature and people, and the development options chosen in the planning processes further confirm this relationship.

The approaches and perceptions characterising the two systems vary considerably in some cases while in others they share some similarities. An attempt was made by Emery (1997: 31) to scrutinise the variations between indigenous 
and modern (which was referred to as scientific) knowledge as tabulated below in a summary of the key aspects that also constitute an interface between the two knowledge systems.

\section{Table 1: The Interface Between Indigenous and Modern Systems}

\begin{tabular}{|c|c|c|}
\hline Aspects of Knowledge & Indigenous Knowledge & Scientific (Modern) Knowledge \\
\hline \multirow[t]{3}{*}{ 1. Scope } & $\begin{array}{l}\text { Sacred and secular together; } \\
\text { includes the supernatural }\end{array}$ & $\begin{array}{l}\text { Secular only; excludes } \\
\text { supernatural }\end{array}$ \\
\hline & $\begin{array}{l}\text { Holistic, integrated - based on } \\
\text { whole systems }\end{array}$ & $\begin{array}{l}\text { Analytical or reductionist - based } \\
\text { on sub sets of the whole }\end{array}$ \\
\hline & $\begin{array}{l}\text { Stored orally and in cultural } \\
\text { practices }\end{array}$ & Stored in books and computers \\
\hline \multirow[t]{4}{*}{ 2. Truth Status } & Assumed to be the truth & $\begin{array}{l}\text { Assumed to be the best } \\
\text { approximation of truth }\end{array}$ \\
\hline & Subjective & Objective \\
\hline & Truth found in nature & $\begin{array}{l}\text { Truth found from human } \\
\text { reasoning }\end{array}$ \\
\hline & $\begin{array}{l}\text { Explanation based on examples, } \\
\text { experience and parables }\end{array}$ & $\begin{array}{l}\text { Explanations based on } \\
\text { hypotheses, theories and laws }\end{array}$ \\
\hline \multirow[t]{4}{*}{ 3. Purpose } & Long-term wisdom & Short-term prediction \\
\hline & Practical life and survival & Abstract, to pass examination \\
\hline & $\begin{array}{l}\text { Powerful predictability in local } \\
\text { areas (ecological validity) }\end{array}$ & $\begin{array}{l}\text { Powerful predictability in natural } \\
\text { principles (rational validity) }\end{array}$ \\
\hline & $\begin{array}{l}\text { Weaker in predictive principles } \\
\text { in distant areas }\end{array}$ & Weaker in local use of knowledge \\
\hline \multirow[t]{4}{*}{$\begin{array}{l}\text { 4. Methods of Teaching } \\
\text { and Learning }\end{array}$} & $\begin{array}{l}\text { Lengthy period of acquisition } \\
\text { ('slow knowledge') }\end{array}$ & $\begin{array}{l}\text { Rapid acquisition } \\
\text { ('fast knowledge') }\end{array}$ \\
\hline & $\begin{array}{l}\text { Learning by living, experiencing } \\
\text { and doing }\end{array}$ & Learning by formal education \\
\hline & $\begin{array}{l}\text { Teaching through examples, } \\
\text { modeling, rituals and story } \\
\text { telling }\end{array}$ & Teaching is didactic \\
\hline & Tested in practical life situations & Tested artificially in examinations \\
\hline
\end{tabular}

Source: Field Data, 2012

The above table brings out some conceptual and methodological issues that characterise the apparently thin divide between the two knowledge systems. For instance, the visioning period is much shorter for modern than it is for indigenous systems. The long-term vision espoused by indigenous systems is a critical ingredient in the sustainability principles. In addition, the approaches and methodologies applied in indigenous systems are generally practical and locally relevant compared to modern systems. Thus, the failure by modern systems' intervention to sustainably contain environmental and development challenges arising mainly from human activities is partially a function of their restricted scope in terms of time and approach. The short-term interventions usually leave 
behind long-term negative implications. On the other hand, modern systems have better knowledge storage devices that make it easy to store, retrieve and share information. Many other disparities are clearly outlined in the table.

\subsection{Modern Environmental Education Systems}

Some modern environmental education systems were looked at to determine the main approaches applied and how environmental education ideals find their way into the planning processes. Thus, the influence of environmental education (EE) in engendering environmentally sensitive development and spatial plans was also assessed with special interest in ascertaining the extent to which such influence could practically be observed from policies and plans and their implementation. Examples from Zambia, Germany and Montenegro have been used.

\subsubsection{Modern Environmental Education Approaches in Zambia}

Generally and ideally whatever strategies a nation applies in attaining desired goals do happen within a defined policy framework. The same was expected even in dealing with environmental aspects. Thus, the nature of environmental education approaches do to some extent reflect the overall policy direction which may or may not relate to some identified ultimate vision. Having a glimpse at the environmental policy instruments therefore becomes a necessary pre-requisite to understanding the underlying mechanisms that influence the chosen systems or approaches of environmental education.

To analyse the government policies on environment, it is pertinent to look at the instruments of environmental policy which (Est, 2003) categorised into three, namely:

- Direct regulation;

- Indirect regulation (economic instruments); and

- Self-regulation (voluntary instruments)

Furthermore, an assessment of the factors that influence choices of policy instruments can also be an integral component of the processes involved in trying to understand a country's overall vision, or metaphorical vision as espoused by Namafe (2006).

With respect to Zambia, there was an apparent tendency to generally embrace direct regulation through law enforcement and indirect regulation through economic incentives. A general neglect of the third strand of selfregulation was quite evident in Zambia. Self-regulation requires thoughtful and active engagement of the public especially through education and the establishment of working linkages. It involves adoption of instruments that internalise environmental-friendly behaviour. This had been demonstrated through an observed strong correlation between environmental awareness and policy intensity as highlighted by Est (2003: 151) that '.. providing environmental information and education and creating co-operation 
structures between the government, companies, NGOs, and citizens are very important environmental policy tools... by doing this, the indispensable support for environmental policy is created.'

The Zambian experience is devoid of this necessary strategy although its importance had apparently been realised. The much emphasis placed on direct regulation in Zambia's modern environmental and nature conservation system had proved ineffective with regrettably disastrous results. The adopted approaches in Zambia were generally undesirable from a sustainability perspective in that they technically alienated the people and eroded the sense of ownership that had been deep rooted in the locals for centuries.

Despite this unfortunate scenario, there was an emerging phenomenon of self-regulation in Zambia that was taking root informally through stakeholder initiatives of engaging the communities without enforcement. This new informal policy instrument, self-regulation, can also be a catalyst for good governance and facilitate the formulation of integrated policies for decision making (UNECE, 2010). The two posters shown in the figure below are an example of the existence of two completely opposite instruments of direct regulation and self-regulation in Zambia.

The billboard at Chirundu National Fossil Forest Monument just issues threats of imprisonment without providing public environmental education where as the Itezhi-tezhi one engages the community in a participatory and educative manner towards self-regulation. The predominance of direct regulation over other strategies

\section{Figure 2: Posters Depicting Direct Regulation (Fossil Forest) and Self- regulation (GMA)}

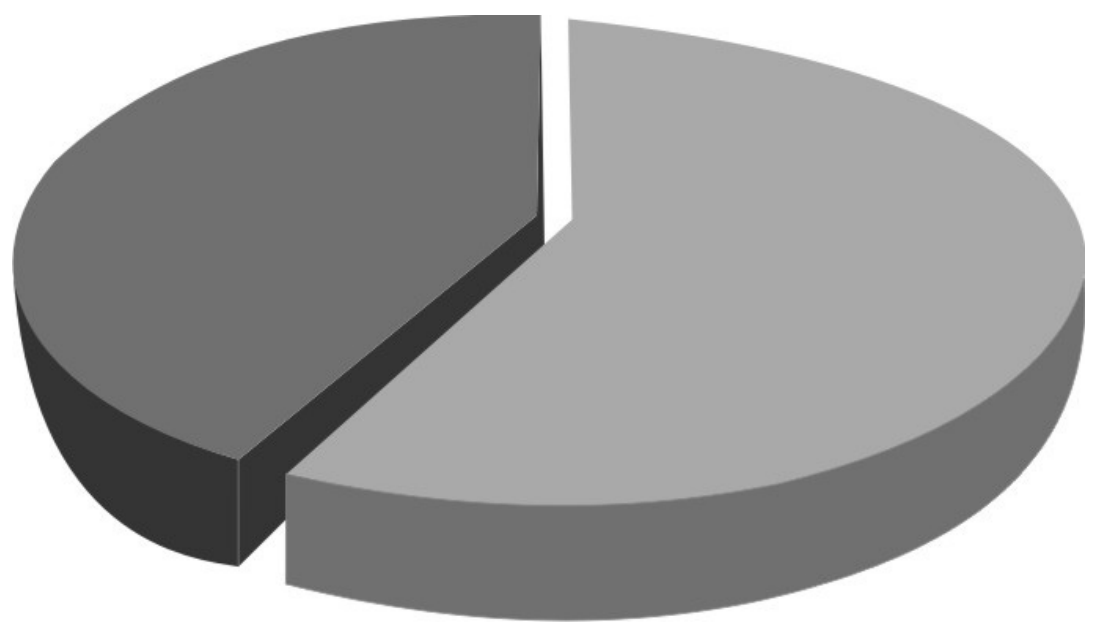

Chirundu Fossil Forest National Monument

Poster (Direct Regulation)

Kafue National Park, Itezhi-tezhi - Mongu Road junction (Self-Regulation) 
does not only sideline the people but also narrows the room for the inclusion of indigenous knowledge systems which could enrich the conventional approaches.

There was, however, an apparent acknowledgement by the Zambian government that public environmental education had the potency to drive attitude change in people's behaviour and bring about self-regulation. For instance, the Ministry of Local Government and Housing prepared and disseminated a 'Make Zambia Clean and Healthy' programme which outlined several generic activities which institutions, the public and individuals were urged to practice in order to improve the state of the environment and personal health in homes, schools, churches, and workplaces. Although this was a government led programme, it was generally a multi-sectoral and multi-disciplinary environmental campaign initiative that involved all government line ministries, Provincial and District Administrations, Local Authorities, Traditional Authorities, Cooperating Partners, Religious Organisations, NGOs, and Community Based Organisations, among others (GRZ, 2011).

In terms of planning related modern environmental education systems, it was established that public officers conducted negligible consultations with local communities in the discharge of their duties. As such, local environmental issues from the viewpoint of the local people did not find their way in both regional and spatial development plans and this accounted for insignificant influence of EE in key development facilitation processes. It was further established from the interviewed GRZ Heads of Departments (HoDs) that, although their duties were generally planning in nature, many (42\%) did not consider planning to be one of their core mandates as illustrated in the pie chart below.

\section{Figure 3: Proportion of Heads of Government Departments in Siavonga that consider Planning to be one of their Core Mandates}

Although all the interviewed heads of government departments did participate in planning activities either for their departments or in collaboration with other stakeholders through district development coordination structures, 46 per cent of them exhibited very weak involvement in planning activities as shown below.

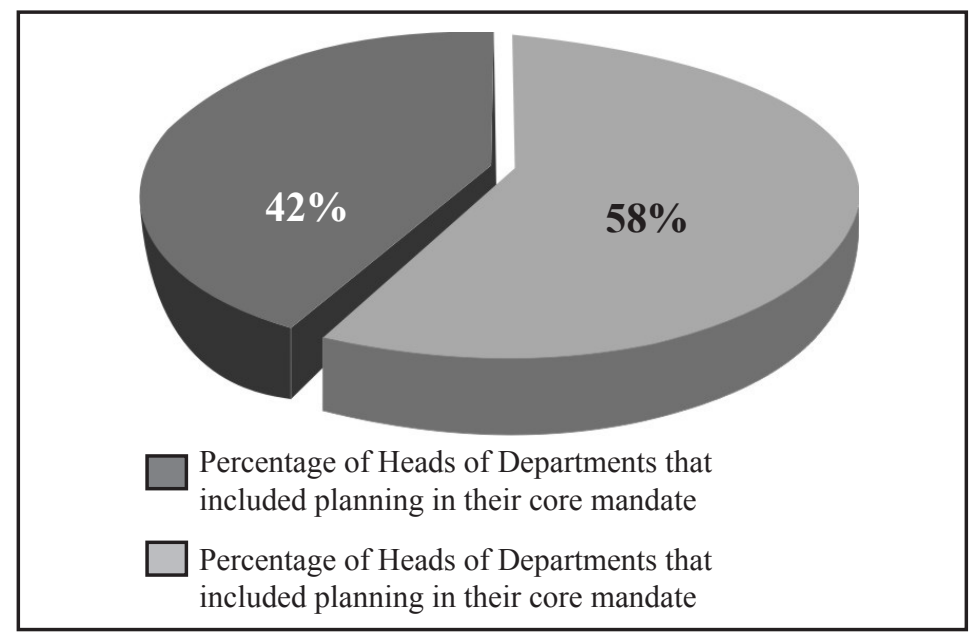

Source: Field Data, 2012 
Figure 4: Respondent HoDs' Perceptions on the Extent of Planning Functions Carried Out

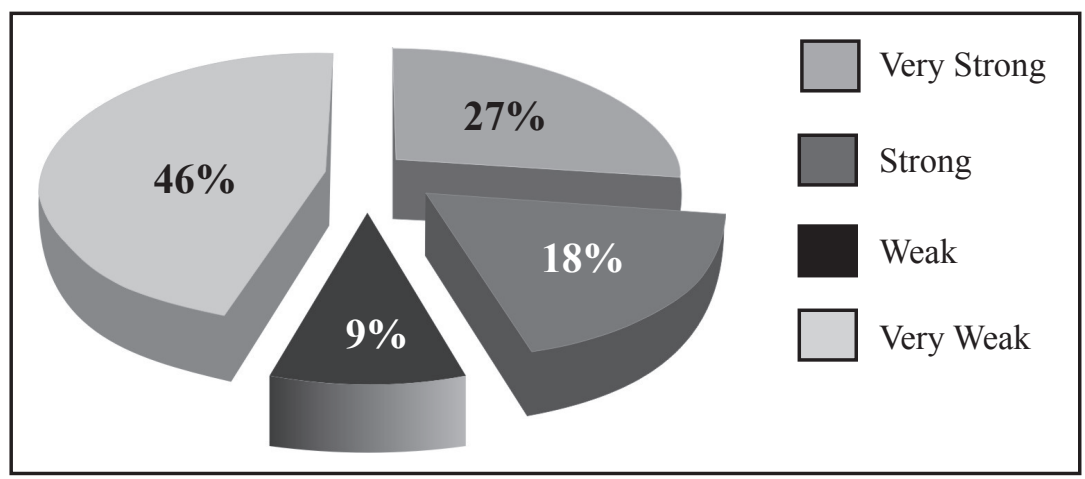

Source: Field Data, 2012

The study also revealed that the governance system had a bearing on the officers' planning capacities at district level. That is, the capacity depreciated or appreciated depending on whether an officer's department is highly centralised or decentralised. HoDs in departments whose ministries had embarked on decentralised governance system showed increased planning capacities, such as education and health sectors, whereas those that were still highly centralised exhibited weak planning capacities as depicted by the figure below.

Figure 5: Relationship between Governance System and Planning Capacities in Government Departments in Siavonga District

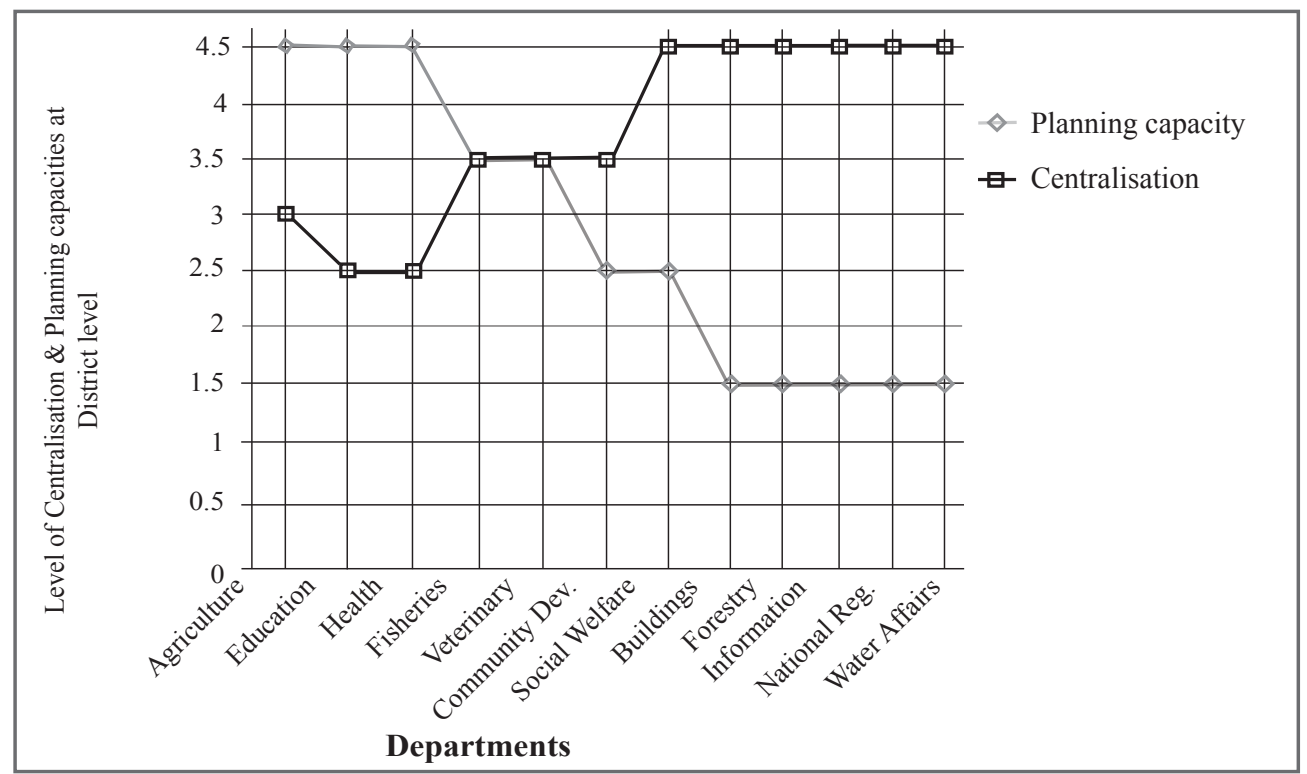

Source: Field Data, 2012 
Although planning capacities appear to be a function of the governance system a department adopted, the extent to which environmental issues were integrated in departmental programmes could not be linked to the governance system. Other factors such as a department's technical orientation could be attributed to that and probably further research on this could help explain the causal factors. The graph in Figure 6 below shows that the governance system does not help to explain environmental integration.

\section{Figure 6: Graph Suggesting that Environmental Integration Does Not Necessarily Depend on Governance System but on Other Factors}

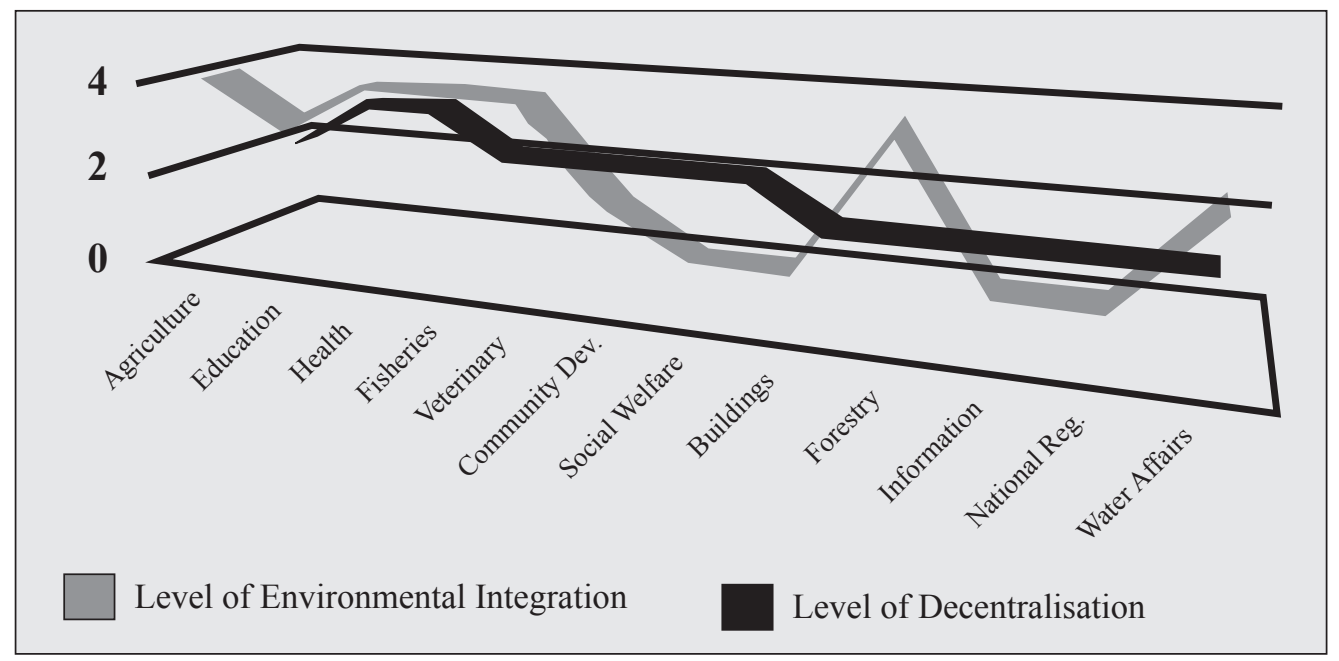

Source: Field Data, 2012

\subsubsection{Modern Environmental Education Approaches in Europe (Germany and Montenegro)}

Unlike Zambia, the main EE approaches these two European countries embraced were self-regulation, participation, education and advocacy. Montenegro went further to formulate an ecological-political ideology that constituted the national vision. Montenegro declared itself an Ecological State in 1991 and all activities should be seen to feed into the vision of this declaration (GRM, 2007). Germany's vision for the school system is to create an 'environmental consciousness and fostering environmentally sound behaviour' (Dempsey et al., 1997: 2).

The two countries prioritised attitude change to ensure self-regulation whereas Zambia still maintained remarkable faith in direct regulation through law enforcement. The strategies by these two European countries were recording admirable strides compared to the approaches prefered in Zambia. The two countries further provided for multiple actors with mutual responsibility in environmental matters. In addition, they have regional networks in combating environmental challenges and enhancing 
environmental advocacy and education. All these initiatives have empirical impact on the planning systems through the establishment of stronger connections with the international processes which included the elements of modern strategic planning.

The strategies used by the named countries may account for stakeholder cooperation in agreed activities which ruled out the relevance of direct regulation. For instance, although 45 per cent of Montenegro's entire territory is under forest cover and about $300 \mathrm{~km}$ coastline, only 7.7 per cent of the country is protected by national legislation and this includes the four national parks (GRM, 2007). The rest of the country's natural resources are 'self-regulated' by the citizens. Further, there are also some coherent linkages between national vision and local operational strategies and regional and continental strategies. For example, following the declaration of Montenegro as an 'Ecological State', a strategic framework (directions for the development of Montenegro as an ecological state) was prepared to operationalise this declaration. This was also incorporated in the National Strategy of Sustainable Development of Montenegro. It had some conceptual linkages at continental level with the ideals of the Pan European Ecological Network which is a concept based on the assumption that underscores the importance of re-establishing interconnectivity between natural and seminatural values in order to counteract physical fragmentation arising from intensification of land use in various parts of Europe over the last decades. This physical fragmentation had also been accused of jeopardising the viability of eco-systems and species populations and, therefore, threatening nature and biodiversity in Europe (Gtz, 2007).

The Pan European Ecological network had provided a platform for cooperation between state governments and the civil society. The latter played two cardinal roles, that is, advocacy and public awareness as well as watch dog over government performance on agreed priorities. For instance, some civil society organisations raised concerns about the Montenegrin government's failure to adhere to the free environmental information ideals and that the public were allegedly denied adequate information by the state (Calovic, V. and Deletic, M., 2008). The contention by the civil society was that although article one of Montenegro's constitution established that Montenegro was an 'ecological state' there were still some unjustifiable gaps in the area of access to environmental information. The Montenegrin government had also not signed the international treaty, the Aarhus Convention, which was the UN/ ECE Convention on access to information, public participation in decisionmaking and access to justice in environmental matters (Darbishire, 2007). The scrutiny by the civil society is symptomatic of enhanced awareness on environmental, governance and planning systems by the stakeholders, a necessary precondition to holding government accountable on these matters. In Zambia, the government is usually held accountable on financial and political decisions and actions made. 
Environmental education has not only been mainstreamed in the school system in Montenegro but in the planning systems too. It had become mandatory in Montenegro to prepare environmental impact assessments (EIAs) to accompany any spatial plans prepared and they form part of the criteria in the approval process of plans. The national spatial planning system acknowledged the necessity to incorporate environmental issues in planning. Efforts had been made by the Montenegrin government to legislate this environmental requirement. With inspiration from the European continent's determination to raise environmental awareness through different strategies and policy reforms, Montenegro revised the spatial planning system to create adequate room for enhancing the integration of environmental issues. At national level, necessary reforms were instituted to reorient the focus of some appropriate ministries towards nature protection (GRM, 2007; UNDP, 2010).

In Germany, the Federal government provided enabling conditions for private sector participation in environmental education and management under the guidance of the Federal Environment Agency headquartered in Dessau. The Federal government had established the Business and Biodiversity Initiative, an international initiative whose goal was to intensify private sector involvement in activities for the conservation and sustainable use of biodiversity (Benemann and Kaplan, 2010). The motivation that had driven the Federal Republic of Germany to embrace such collaborative and inclusive environmental awareness and practical measures could have been explained more vividly by the Federal Environment Agency on the posters shown below by establishing linkages between economic activities and environmental systems.

Figure 7: Educative Posters at the Federal Environment Agency Public Foyer, Dessau, Emphasising the Importance and Fragility of Nature and the Threats Posed by Human Activities and the Need for Companies to Mainstream Ecological Considerations in their Operations

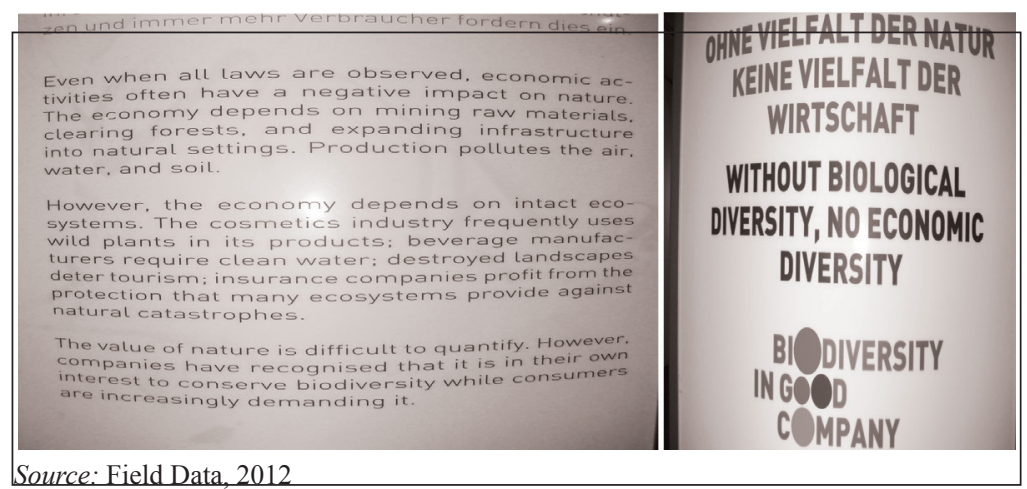




\subsection{Indigenous Environmental Education Approaches}

Indigenous knowledge systems have been applied in real life situations for centuries and their relevance to contemporary development challenges could still be upheld. Described below are some environmental education approaches that had been employed in indigenous societies, particularly among the BaTonga and Ma-Lozi societies.

The main indigenous EE approaches among the Ba-Tonga and Ma-Lozi people of Siavonga and Mongu districts respectively were: observation, experimenting, replication of antecedent knowledge and religious and belief factors. The indigenous systems dwelt more on attitude and relationship with nature, a critical requirement to attain self-regulation.

Among the Tonga people, there were appreciable levels of autonomy in terms of determining their destinies. The traditional leadership structure recognised the independence of area chiefs. Thus, the Tonga chiefs enjoyed absolute traditional autonomy in the areas under their jurisdiction without being answerable to any other chief. This created a conducive environment for local ownership of any development interventions and provided for enhanced self-regulation among the communities.

In the Lozi society, on the other hand, there was a hierarchical leadership structure with clearly defined accountabilities at all levels from village heads, to area indunas, to district chiefs and up to the Litunga. This was basically a centralised governance system with some devolved functions at respective lower levels. It was through this system that certain developmental projects could be undertaken by the communities. Further, valuable components of the physical environment such as forests, water courses and wildlife could be accounted for and conserved through collective efforts.

Methodologically, the Barotse system, and many other indigenous systems, did not pay special attention to individual achievement but rather to community effort. Thus, working on community projects like creating and maintaining canals generated pride in the workers and had a different concept of reward from the modern money economy. These were critical values that formed a firm foundation for sustainable communities but were regrettably lacking in the modern systems.

Generally, the Barotse indigenous education and development system consisted of the following approaches:

- Instilling a sense of personal and community pride in having a sound and functioning environment and the belief that there was not any other part on earth that was as beautiful and blessed as Barotseland, a notion that was embedded in the first stanza of the indigenous national anthem for Barotseland;

- A combination of direct regulation (through legislative measures and the courts) and self-regulation (through sense of ownership and pride);

- Instilling personal responsibility through the religious dimension where natural resources or environment in general were believed to have been 
given to humankind by God (Nyambe) who in turn expected humanity to manage such resources sustainably;

- Direct transfer of skills, knowledge and beliefs through clan, family lineage, ceremonies and rituals.

\subsection{Opportunities for Synergy Formulation between Modern and Indigenous Environmental Education Systems - a Global Perspective}

A number of opportunities were identified that could facilitate the formulation of a synergy between the two systems at both global and local levels. From a global perspective, Montenegro and Germany provided encouraging examples of the possibilities of synergy formulation. In the case of Montenegro, for instance, the government made necessary reforms to the education system that were aimed at addressing the concept of sustainability. Through these reforms the Montenegrin government demonstrated the possibility of having a synergy of education systems. The government (GRM, 2007: 53), through the Ministry of Education and Science, emphasised that 'apart from the regular education system, considerable attention will be given to the development of the system of informal education to enable life-long learning and recognition of newly acquired knowledge in the system of national vocational qualification.'

In Germany, there were constant reforms in the planning systems to address the missing links between the bodies of knowledge through integration of various systems and multiple stakeholders. Notable among these measures was the emphasis on drawing upon past experiences in order to shape the future. This drew attention to indigenous knowledge which was generally richer than the modern one when applied at local level. The scientific relevance of some indigenous knowledge systems was gradually revealed through modern research efforts. This was a tested integration at this level which could easily lead into a complete synergy. The poster shown in the Figure below portrays some of the strategies used in Germany to invoke reflection on merging indigenous ideas with modern ones in the education and planning systems. 
Figure 7: A Poster Promoting a Synergy Oriented Message in Planning, Dresden Germany

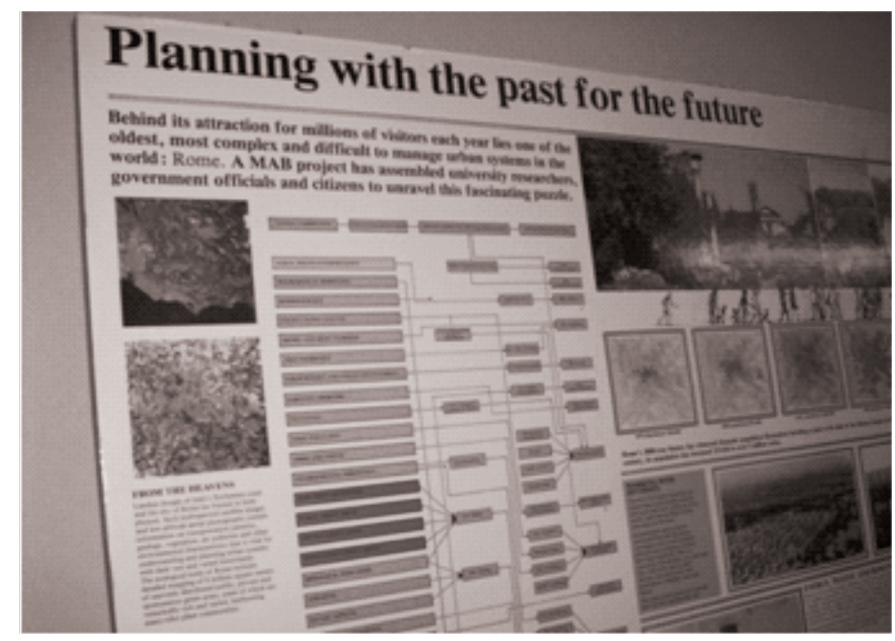

Source: Field Data, 2012

When exploring opportunities for synergy formulation, a variety of factors were identified which this study classified into three which should collectively lead to sustainability: primary factors; secondary factors, and tertiary factors. The study considered the primary factor to be a necessary and unavoidable ingredient in the synergy formulation process without which no genuine synergy could come forth. This factor was culture. The secondary factor was the capacity by society, nations and the world to realise the importance of culture in this business, and the tertiary factor was the willingness by the enlightened society, nations or the world to act accordingly. Thus, the transition from ignorance to enlightenment alone was not enough and would not be relevant if it was not accompanied by the capacity and willingness to transform this enlightenment into practical reality.

The relevance of culture was steadily being recognised in the Local Government system at the international level and since planning is a key function of local government, culture is finding its right place in the planning systems. For instance, the United Cities and Local Governments (UCLG, 2009) noted that the sustainable development paradigm had included those values which could propel a society's progress, values such as diversity, creativity or critical thinking and that these values constituted part of the inherent cultural processes. It was from this realisation that the UCLG questioned the efficacy of the three universally accepted pillars of sustainable development, i.e. economic, social and environment, without culture. The ULCG thus adopted culture as a fourth pillar of sustainability. Since culture could be described as the knowledge storage device for indigenous systems, its inclusion could lubricate the obstacles that stifle the integration of indigenous knowledge systems in the modern mainstream systems and facilitate a complete synergy. 


\subsection{Opportunities for Synergy Formulation between Modern and Indigenous} Environmental Education Systems - a Local Perspective

The validity of indigenous knowledge has been noticed in Zambia at local levels in many cases. In Mongu district, for instance, the failure by modern systems to maintain their relevance to local environments was evidenced over the construction of the Mongu-Kalabo road across the Barotse flood plain. The road project became costly due to frequent failures occasioned by the destruction of bridge structures by the flood waters. The locals' indigenous knowledge about the general behaviour of flood waters was not sought for by the contractors and consultants who were unquestionably qualified and experienced engineers.

The locals argued that flood waters had a double trajectory characterised by both lateral and vertical flows and that modern engineers could have apparently paid more attention to lateral flow. They further explained that the vertical flow was a two-way movement, up-and-down, that is, when it rains, the rain water percolates into the soil (downward flow) and when the soil reaches infiltration capacity, inundation occurs and generates lateral flow on the surface due to differential gradient. Further, the vertical (upward) flow is also initiated from ground water recharge to join the surface flood waters. These movements undermine the foundation of road structures, particularly bridges and culverts. The double action is intensified by vertical flow, which undermines the foundations, and the lateral flow which causes dislocation of foundations and eventually the collapse of superstructures. The locals witnessed the destructive behaviour of flood waters for centuries, including the exhumation of bodies in cemeteries when they get inundated especially if the area was underlain by a thick layer of sand.

\subsection{The Proposed Synergy of Systems, Characteristics and the Strategic Framework}

The proposed synergy has drawn insight from the interface presented earlier by focusing on the positive attributes of the respective systems. The synergy basically involved the identification and collection of these good attributes so as to counter the negative aspects imbedded in each system and to create a strengthened, locally relevant and globally appropriate system with strong vertical and horizontal linkages at local, regional and global levels and encompassing all stakeholders. The framework shown in the figure below elaborates the process involved in identifying synergy worth elements. 


\section{Figure 8: Proposed Synergy Formulation Strategic Framework}

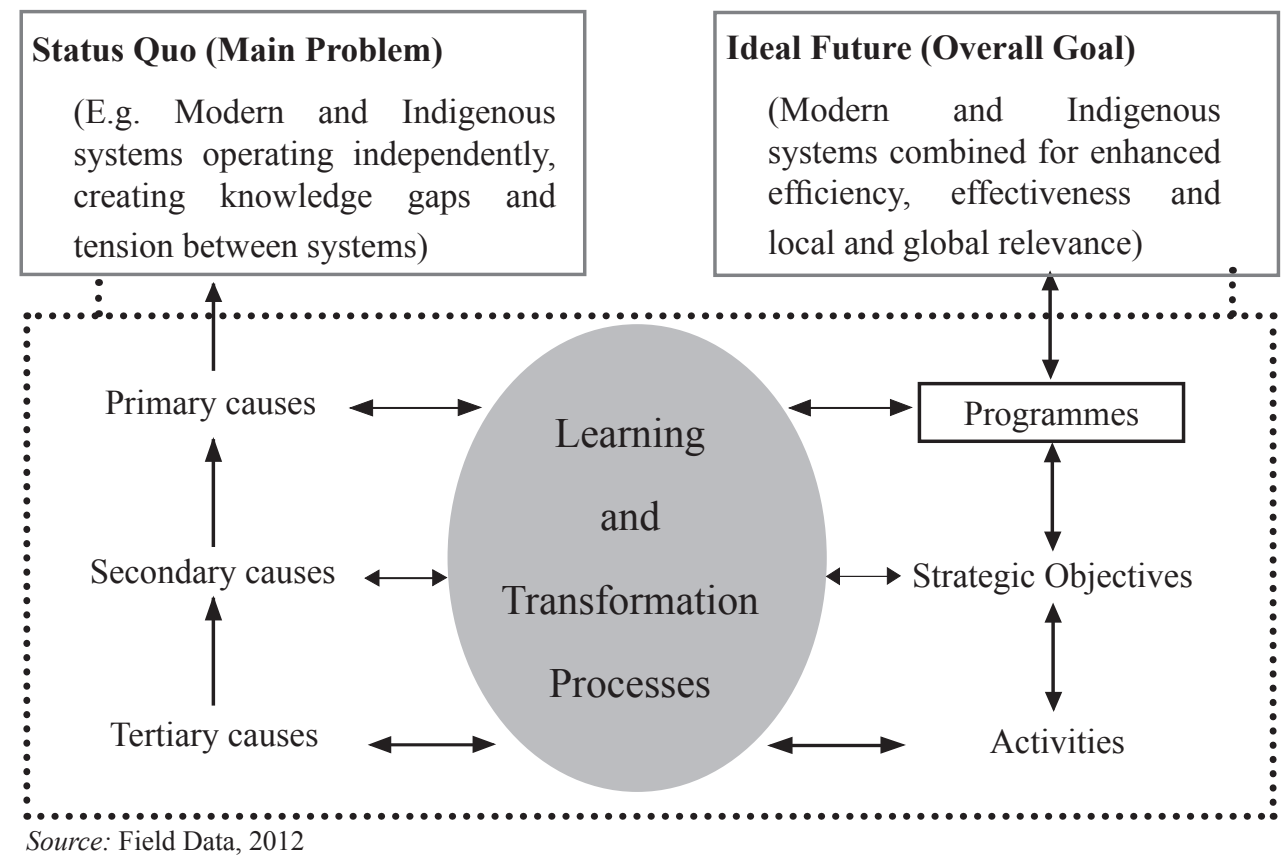

As illustrated above, the proposed synergy does not seek to create new systems but to modify existing ones through an integrated approach. It seeks to transform contemporary local and regional problems into development visions and objectives and turn the identified root causes into a means to the desired scenario. The synergy, therefore, adds additional lens through which to explore available alternatives in creating sustainable communities.

\section{REFERENCES}

Benemann, A. and Kaplan, S. (2010), One Nature-One World- Our Future: Results of the Germany CBD Presidency 2008 to 2010, Federal Ministry for the Environment, Nature Conservation and Nuclear Safety, Berlin.

Calovic, V. and Deletic, M. (2008), The Green Maze: Access to Information on Environment. Podgorica: Foundation Open Society Institute.

Darbishire, H. (2007), Free Access to Information and Secrecy of Data in Montenegro:

Law Comments with Recommendations. Podgorica: Network for the Affirmation of Non-Governmental Sector,

Dempsey, R., Gresele, C., Bogeholz, S., Martens, T., Mayer, J., Rode, H. and Rost, J. (2007), Empirical Studies on Environmental Education in Germany: Contributions by the Institute for Science Education. Kiel Germany: Institute for Science Education.

Emery, A.R. (1997), Guidelines for Environmental Assessment and Traditional Knowledge: A Report from the Centre for Traditional Knowledge of the World Council of Indigenous People, Ottawa. 
Est, P.V. (2003), Separate Pasts, Shared Future: An Environmental Policy Comparison, the Czech Republic and the Netherlands 1948 - 2001. Prague: Institute for Environmental Policy.

Government of the Republic of Montenegro (2007), The Future Begins Today, We Create It: National Strategy of Sustainable Development of Montenegro. Ministry of Tourism and Environmental Protection, Podgorica.

Government of the Republic of Zambia (2011), Make Zambia Clean and Healthy Campaign Programme ( $2^{\text {nd }}$ Edition), Ministry of Local Government and Housing, Lusaka.

Gtz(2007), Skadar Lake-Concept on Cross-Border Development: A Spatial Perspective. Podgorica: Gtz.

Namafe, C.M. (2006), Environmental Education in Zambia: A Critical Approach to Change and Transformation. Lusaka: University of Zambia Press.

UNDP (2010), Spatial Planning Factsheet: Spatial Planning Support Project in Montenegro, UNDP, Podgorica.

UN-ECE (2010), Policy Framework for Sustainable Real Estate Markets: Principles and Guidance for the Development of a Country's Real Estate Sector. Geneva: UN-ECE.

United Cities and Local Governments (2009), Culture 21 - Culture and Sustainable Development: Examples of Institutional Innovation and Proposal of a New Cultural Policy Profile. Barcelona: Barcelona City Council/UNESCO. 